might have survived had the type of accident been different and allowed casualties to be rescued more quickly. This emphasizes the need for early and rapid extraction of the injured.

The efficiency of sorting and resuscitation by medical teams at the site was reflected both by the fact that only two patients were dead on arrival and by the absence of airway problems among those who were alive.

Contaminated soft-tissue injuries were treated by debridement and laying open, followed at two to three weeks by skin grafting. All cases treated healed without complication. One patient aged 19 years was trapped by the left foot. It proved impossible after 12 hours of effort to free her, and we therefore decided to perform an above-ankle amputation. This was done under ketamine anaesthesia with the patient vertical. The operation was performed in semi-darkness with the surgeon underneath. No tourniquet could be applied. Difficulty was experienced because the limited field impeded saw movement, and a powered saw would have been a great advantage. In the absence of a tourniquet a fast-running blood drip was used.

The clinical features and initial course of the two patients with the crush syndrome were similar and conformed well with the description by Bywaters and Beall. ${ }^{3}$ Both had been crushed for over six hours, and on arrival at hospital hyperkalaemia had developed. The diagnosis was suspected in both cases. Normal peripheral pulses and the appearance of healthy looking, if bruised, limbs should not lull the clinician into believing all is well. Early potassium estimation and catheterization for a urine sample should be performed on suspicion. On arrival at hospital patients should immediately be connected to an electrocardiograph to assess the effects of hyperkalaemia, and steps should be taken to reduce the serum potassium levels. A cardiac arrest team should be immediately available, as should the services of a nephrology department capable of peritoneal dialysis and haemodialysis. The rationale of fasciotomy was to aid arterial perfusion in the hope of preventing further muscle damage. The disappointing outcome in these two cases brings into question whether early removal of the limb should have been performed. As the legs were crushed at the groin high bilateral amputations would have been necessary.

Though there is some experimental evidence that limb perfusion reduces the biochemical effects of limb crushing, ${ }^{4}$ there seems to be little information about the value of amputation. In a report of three cases of the syndrome in coal miners ${ }^{5}$ the authors advised against amputation, though they offered no evidence for this counsel. In reports of the crush syndrome among Vietnam war casualties ${ }^{6} 7$ the place of amputation was not discussed. Amputation after the renal lesion had become established produced little benefit. ${ }^{7}$ Mortality from the crush syndrome is high, and despite modern intensive care, which offered the maximum possible in supportive treatment, both patients died. The value of local treatment by perfusion or amputation in clinical practice remains unknown, but a more aggressive approach to the local lesion might have improved the outcome.

Requests for reprints should be addressed to: Mr. J. O. Robinson, Department of Surgery, St. Bartholomew's Hospital, London EC1A 7BE.

\section{References}

1 Surgery of Violence. London, B.M.A., 1975.

2 Fire, 1975, 68, No. 840, special supplement.

3 Bywaters, E. G. L., and Beall, D., British Medical fournal, 1941, 1, 427.

4 Thompson, W. W., and Campbell, G. S., Annals of Surgery, 1958, 149, 235.

${ }^{5}$ Bentley, G., and Jeffreys, T. E., Fournal of Bone and Foint Surgery, 1968, $50 B, 588$.

6 Shinaberger, J. H., Military Medicine, 1965, 130, 1078.

${ }^{7}$ Fitts, C. T., et al., fournal of Trauma, 1966, 6, 507.

\title{
Retinoblastoma: A Study of Natural History and Prognosis of 268 Cases
}

\author{
E. L. LENNOX, \\ G. J. DRAPER, \\ B. M. SANDERS
}

British Medical fournal, 1975, 3, 731-734

treatment only three died during the subsequent period of follow-up, which varied from one to seven years. Among children with retinoblastoma treated between 1949 and 1968 nine died between seven and 13 years later of other cancers: seven from osteosarcomas, one from

\section{Summary}

The natural history and prognosis of retinoblastoma were analysed using data relating to the 268 cases registered during 1962-8 in England, Scotland, and Wales. The children were followed up for a minimum of four years; the proportion surviving for four years was $86 \%$. The most important factors affecting survival rate were the stage of the tumour at diagnosis and the hospital of treatment. Of children surviving for three years after

\footnotetext{
Childhood Cancer Research Group, Department of the Regius Professor of Medicine, Oxford University, Oxford. OX2 6JN G. J. DRAPER, M.A., Director

E. L. LENNOX, M.B., CH.B., Research Assistant B. M. SANDERS, B.A., Research Assistant
}

\begin{abstract}
Introduction
Children with retinoblastoma registered in England, Scotland, and Wales during 1962-8 were notified to the Oxford Survey of Childhood Cancers by regional cancer registries. They comprised about $3 \%$ of all registered cases of malignant disease in children aged under 15 years in Britain during these years. Parents were interviewed by their family doctors if the children were still alive or by medical staff organized by health departments if the children had died. A full family history and details of treatment and the course of the illness were obtained from the family doctor and from hospital records. The surviving children were followed up for at least four years after treatment, and in some cases for as long as 10 years.
\end{abstract}


TABLE I-Numbers of Patients with Retinoblastoma in Various Categories

\begin{tabular}{|c|c|c|c|c|c|c|c|c|c|c|}
\hline & \multicolumn{3}{|c|}{ Familial Cases } & \multicolumn{3}{|c|}{ Sporadic Cases } & \multicolumn{3}{|c|}{ All Cases } \\
\hline & & Boys & Girls & All & Boys & Girls & All & Boys & Girls & All \\
\hline $\begin{array}{l}\text { Unilateral cases } \\
\text { Bilateral cases }\end{array}$ & $\begin{array}{ll}\cdots \\
\cdots\end{array}$ & 25 & $\begin{array}{r}7 \\
15\end{array}$ & $\begin{array}{r}9 \\
40\end{array}$ & $\begin{array}{l}69 \\
37\end{array}$ & $\begin{array}{l}79 \\
34\end{array}$ & $\begin{array}{r}148 \\
71\end{array}$ & $\begin{array}{l}71 \\
62\end{array}$ & $\begin{array}{l}86 \\
49\end{array}$ & $\begin{array}{l}157 \\
111\end{array}$ \\
\hline All cases $\ldots$ & $\ldots$ & 27 & 22 & 49 & 106 & 113 & 219 & 133 & 135 & 268 \\
\hline
\end{tabular}

\section{The Tumours}

The diagnosis of retinoblastoma was confirmed histologically in 241 cases $(90 \%)$. There was no histological record in 10 cases, and in a further 17 cases there was no enucleation and therefore no histological confirmation. Table I shows the sex distribution in the various categories; unilateral and bilateral, sporadic, and those with a family history of the illness. Of the 268 tumours $111(41 \%)$ were bilateral. The proportion of bilateral tumours reported in the literature varies from $8 \%$ to $43 \%$ and is commonly stated to be $30 \%$. Of the unilateral tumours 80 were in the right eye and 77 in the left eye. Forty-nine children-40 with bilateral and 9 with unilateral retinoblastomahad a family history of retinoblastoma.

\section{Natural History}

The presenting symptoms and signs were known in 224 cases. The white pupil or cat's eye reflex was found in $\mathbf{1 7 0}$ of these, either alone or associated with other symptoms or signs. Squint was noticed in $\mathbf{5 4}$ cases and other less common findings were poor vision, painful eye, pupil irregularity, and hyphaema. Nineteen asymptomatic cases were detected by the routine examination of offspring or siblings of known patients with retinoblastoma. In 24 cases the presentation was unknown and in one child the retinoblastoma was a chance finding during a visit to the doctor for a different reason.

\section{AGE AT ONSET}

The age at onset was known for 259 children, either from first recorded sign or symptom or from the onset date given on the cancer registration abstract. As expected, the familial cases tended to be detected much earlier than the sporadic cases by the routine eye examination given from birth to children who have close relatives with retinoblastoma. The bilateral tumours had a much earlier average age of onset (8.0 months) than the unilateral (25.7 months) and it might be thought that the number of familial cases among the bilateral tumours accounted for this difference. If one excludes all the familial cases, however, and takes into account only the figures for the sporadic cases there was still a highly significant difference of 17 (S.E. 1.9) months between the mean age at onset of 9.5 months for the bilateral cases and 26.5 months for the unilateral cases $(P<0.001)$.

For $94 \%$ of the cases we were able to discover the dates of first symptom of the tumour, first examination by a doctor, and first treatment. Table II shows the mean intervals between these dates for survivors and for those patients who died of retinoblastoma. There was more delay in treatment in the unilateral than the bilateral cases, but this was at least partly accounted for by the fact that there was more delay for older children; there was also, as expected, more delay in treating the sporadic cases than those which were familial. A larger mean interval between onset and treatment was observed for children who died of retinoblastoma (6.6 months) than for the survivors (3.8 months). This difference existed in bilateral and unilateral cases and for both older and younger children.
In $92(83 \%)$ of the bilateral cases the tumours were detected simultaneously in both eyes. The longest interval between the dates of onset of the tumours in the two eyes was 19 months.

\section{AGE AT FIRST TREATMENT}

The ages of the children at first treatment for retinoblastoma ranged from five days to 10 years. The youngest child-a familial casehad an eye enucleated when five days old, while the oldest-a sporadic case-was treated at the age of 10 after first showing symptoms seven months earlier. This child was alive and well four years later. The mean age at first treatment was 30.9 months in the unilateral cases and 10.8 months in the bilateral cases; this reflects the difference in the ages at onset and the longer delay in treatment of unilateral cases. Similar differences between the ages at treatment of unilateral and bilateral tumours have been reported by Mork, ${ }^{1}$ Jensen, ${ }^{2}$ and Leelawongs and Regan. ${ }^{3}$

\section{TREATMENT}

Because of the difference in the nature of the cases the treatment of unilateral and bilateral cases was studied separately. Table III shows the initial and subsequent treatments in 157 unilateral and 111 bilateral cases and the number of children in each category who died. Altogether 24 children with unilateral tumours and 15 with bilateral tumours died from retinoblastoma. Some vision was retained by 68 of the 96 survivors from bilateral retinoblastoma.

TABLE III-Initial and Further Treatment of Patients with Unilateral and Bilateral Retinoblastoma. Numbers of Patients who Died from Retinoblastoma are Given in Parentheses

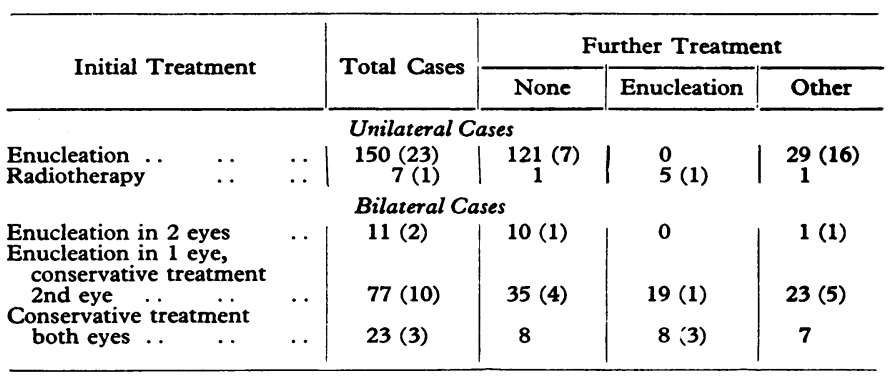

Chemotherapy was used as an adjunct to other forms of treatment but never as the sole method. It was used to treat 44 children with bilateral tumours, 28 initially and 16 during a later course of treatment. Four of these children died. Only nine children with unilateral tumours had chemotherapy treatment, four initially and five in a later course. There were five deaths amongst these nine children.

TABLE II-Mean Intervals (Months) for Patients in Various Categories

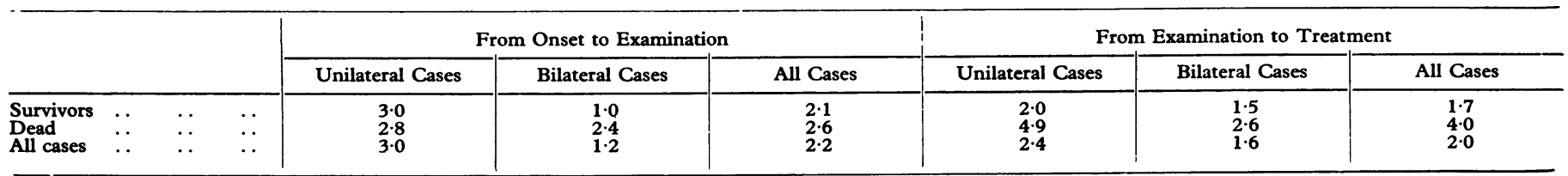


The high proportion of deaths among children with unilateral tumours treated by chemotherapy may indicate that the treatment was used for tumours at an advanced stage and when other treatment had failed. The use of chemotherapy in the treatment of retinoblastoma was less common by 1967. About one in four cases were treated in this way from 1962 to 1966; this proportion had fallen to one in 20 by 1968.

\section{RECURRENCES AND METASTASES}

At least one further course of treatment to an affected eye was required for 63 children. A definite intraocular recurrence was noted in 47 of these children ( 44 bilateral cases). All but three of these recurrences were noted within two years of the original treatment. In 29 out of these 47 children $(62 \%)$ further courses of radiotherapy or light coagulation proved adequate. We could not determine from our data whether the other 16 children ( 13 bilateral cases) who required further treatment had also suffered a recurrence or if the initial treatment had failed to arrest the original tumour. Only two of these children $(12.5 \%)$ responded to further radiotherapy.

Metastases developed in 40 children. These were all clinically detectable within four years of the original treatment and from these there was only one survivor. This child, who had radiotherapy for an extraocular extension of the tumour, was alive and well nine years later. Only six children who had had a recurrence subsequently developed metastases-all within two years of the recurrence. They all died within six months of the detection of the metastases. The sites of metastases were ascertained from hospital notes and death certificates. A full necropsy had been performed on 12 children. In 32 children the metastatic spread was to local sites; eight to skull bones, nine orbital, and 15 intracranial. Involvement of the optic nerve beyond the lamina cribrosa had been noted in the pathologist's report on the enucleated eye in 12 of these children. In eight children the initial metastases were to distant sites: three were found in bones other than the skull, two were widespread, and in three the diagnosis of carcinomatosis was made without the actual sites being specified.

\section{Prognosis}

Of the 268 patients 228 were followed up and found to be still alive four years after treatment. One child died in an accident within a year of treatment and one was lost to follow-up two years after treatment. These two cases were excluded from the analysis of survival rates. One four-year survivor died from retinoblastoma metastases five years after treatment and one from osteosarcoma of the orbit seven years after treatment. One child died from pneumonia seven years after treatment, having had no tumour recurrence. The survival curve for 266 cases is shown in the fig. The four-year survival rate was $85.7 \%$ $84.5 \%$ for unilateral and $87.4 \%$ for bilateral tumours. Equal proportions of boys and girls died within four years of treatment. The overall survival figure of $86 \%$ compares with $81 \%$ for the U.S. in $1960-7,{ }^{4}$ which was probably influenced by the higher mortality for non-white children.

\section{STAGING}

The five-part staging of Reese and Ellsworth ${ }^{5}$ commonly used to group retinoblastoma cases requires more detailed clinical information than that available for most of the cases in this study. We therefore

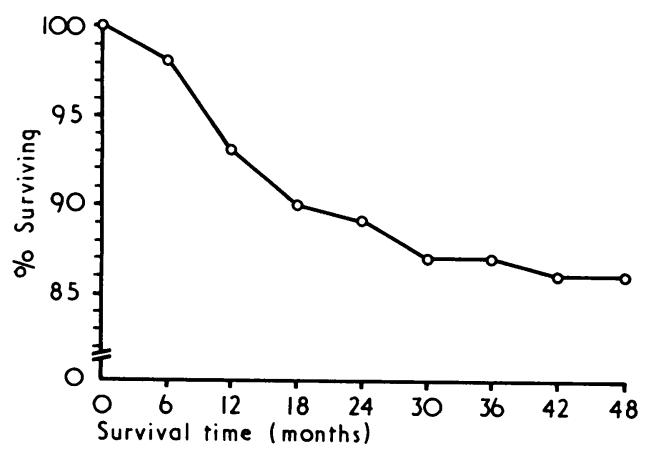

Percentage of all patients with retinoblastoma surviving at various intervals after initial treatment.
TABLE IV-Numbers of Patients and Survival Rate by Stage at Diagnosis

\begin{tabular}{|c|c|c|c|c|}
\hline Stage & Definition & $\begin{array}{l}\text { No. of } \\
\text { Patients }\end{array}$ & $\begin{array}{c}\text { No. of Deaths } \\
\text { Within } \\
\text { Four Years' } \\
\text { Treatment }\end{array}$ & $\begin{array}{c}\text { Four-year } \\
\text { Survival } \\
\text { Rate } \\
\%\end{array}$ \\
\hline $\begin{array}{l}1 \\
2 \\
3 \\
4 \\
5 \\
6\end{array}$ & $\begin{array}{l}\text { Single tumour } \\
\text { Multiple Islands } \\
\text { Retinal detachment .. } \\
\text { Intraocular spread } \\
\text { Optic nerve involved } \\
\text { Extraocular spread .. } \\
\text { No record of stage .. }\end{array}$ & $\begin{array}{r}77 \\
21 \\
50 \\
30 \\
33 \\
5 \\
50\end{array}$ & $\begin{array}{r}2 \\
2 \\
6 \\
8 \\
8 \\
11 \\
5 \\
4\end{array}$ & $\begin{array}{r}97 \\
90 \\
88 \\
73 \\
67 \\
0 \\
\end{array}$ \\
\hline
\end{tabular}

used a simple staging to group the cases according to recorded findings of the status of the tumour at diagnosis. In the case of bilateral tumours the staging was based on the more seriously affected eye. Table IV shows the stage in the 216 cases in which the extent of the tumour at diagnosis was known and the proportion of children surviving four years in each category.

\section{HOSPITAL OF TREATMENT}

The hospitals where the children were treated were divided into three categories. Ninety-seven children received their initial treatment at one of two London hospitals (one a specialist eye hospital) which work closely together for the treatment of retinoblastoma. We grouped these two hospitals together (group 1). Other specialist eye hospitals (group 2) treated 55 children, the largest number treated at any one hospital being 10 . The remaining 114 children were treated elsewhere (group 3). Table V shows the numbers of patients who were initially treated in each category of hospital and the proportions of survivors. The more favourable survival figures for group 1 are investigated in detail below in conjunction with the stage of the tumour and age at diagnosis.

TABLE v-Type of Hospital at which Initial Treatment was Received. Numbers of Patients who Died from Retinoblastoma are Given in Parentheses

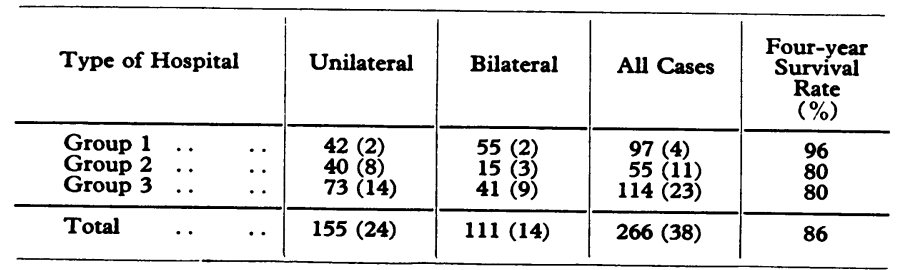

\section{FACTORS INFLUENCING SURVIVAL RATES}

Factors that might influence the four-year survival rate include the age and sex of the patient, the stage of the tumour, whether it was unilateral or bilateral, and the hospital at which the patient was treated.

There was no difference in the survival rate for boys and girls, and in all the analyses which follow the data for the two sexes have been combined. The effects on prognosis of age, stage, and position of the tumour are more difficult to elucidate because of the mutual interrelationship of these factors. The 266 cases included in the analysis of four-year survival rates are shown in table VI.

Death is relatively unlikely to occur in children less than 1 year old at diagnosis. In fact only six deaths were observed in this age group, all among the 65 children with bilateral tumours, and the overall death rate among the younger children was thus only $6.9 \%$. The death rate among the older children-that is, those diagnosed above the age of 1 -was $17.9 \%$. In this age group the survival rates for the unilateral and bilateral cases were almost identical. The explanation of the lower survival rate in the older age group seems to be that children diagnosed above age 1 in either the unilateral or bilateral group were more likely to have a tumour in an advanced stage than were the younger children. There was a strong relation between stage and prognosis for both unilateral and bilateral cases, which accounted for the poorer prognosis of the older children.

In this series 97 children were treated at two hospitals (group 1). The survival rates for group 1 were compared with those for all other hospitals (table VI). The results for group 1 were better than 
TABLE vi-Numbers of Patients who Died and Survivors Four Years after Treatment Subdivided According to Age, Stage, Type of Hospital, and Position of Tumour

\begin{tabular}{|c|c|c|c|c|c|c|c|c|c|c|c|}
\hline \multirow{3}{*}{ Stage } & \multirow{3}{*}{$\underset{\text { (Years) }}{\text { Age }}$} & \multicolumn{4}{|c|}{ Unilateral } & \multicolumn{4}{|c|}{ Bilateral } & \multirow{2}{*}{\multicolumn{2}{|c|}{$\frac{\text { All Cases }}{\text { All Hospitals }}$}} \\
\hline & & \multicolumn{2}{|c|}{ Group 1 Hospitals } & \multicolumn{2}{|c|}{ Other Hospitals } & \multicolumn{2}{|c|}{ Group 1 Hospitals } & \multicolumn{2}{|c|}{ Other Hospitals } & & \\
\hline & & Alive & Dead & Alive & Dead & Alive & Dead & Alive & Dead & Alive & Dead \\
\hline $\begin{array}{r}1 \\
2 \\
3 \\
4 \\
5 \\
6 \\
\text { Not } \\
\text { recorded }\end{array}$ & $\begin{array}{l}<1 \\
\geqslant 1 \\
<1 \\
\geqslant 1 \\
<1 \\
\geqslant 1 \\
<1 \\
\geqslant 1 \\
<1 \\
\geqslant 1 \\
<1 \\
\geqslant 1 \\
<1 \\
\geqslant 1\end{array}$ & $\begin{array}{l}1 \\
9 \\
0 \\
2 \\
0 \\
8 \\
0 \\
5 \\
0 \\
5 \\
0 \\
0 \\
2 \\
8\end{array}$ & $\begin{array}{l}0 \\
0 \\
0 \\
0 \\
0 \\
0 \\
0 \\
0 \\
0 \\
1 \\
0 \\
1 \\
0 \\
0\end{array}$ & $\begin{array}{r}7 \\
24 \\
1 \\
2 \\
4 \\
15 \\
0 \\
5 \\
1 \\
8 \\
0 \\
0 \\
6 \\
18\end{array}$ & $\begin{array}{l}0 \\
1 \\
0 \\
0 \\
0 \\
4 \\
0 \\
5 \\
0 \\
9 \\
0 \\
2 \\
0 \\
1\end{array}$ & $\begin{array}{r}13 \\
6 \\
3 \\
3 \\
6 \\
5 \\
2 \\
4 \\
2 \\
3 \\
0 \\
0 \\
4 \\
2 \\
\end{array}$ & $\begin{array}{l}0 \\
0 \\
1 \\
0 \\
0 \\
0 \\
0 \\
0 \\
0 \\
1 \\
0 \\
0 \\
0 \\
0\end{array}$ & $\begin{array}{r}11 \\
4 \\
6 \\
2 \\
3 \\
3 \\
2 \\
4 \\
2 \\
1 \\
0 \\
0 \\
5 \\
1 \\
\end{array}$ & $\begin{array}{l}0 \\
1 \\
0 \\
1 \\
1 \\
1 \\
0 \\
3 \\
0 \\
0 \\
1 \\
1 \\
3 \\
0\end{array}$ & $\begin{array}{r}32 \\
43 \\
10 \\
9 \\
13 \\
31 \\
4 \\
18 \\
5 \\
17 \\
0 \\
0 \\
17 \\
29 \\
\end{array}$ & $\begin{array}{r}0 \\
2 \\
1 \\
1 \\
1 \\
5 \\
0 \\
8 \\
0 \\
11 \\
1 \\
4 \\
3 \\
1 \\
\end{array}$ \\
\hline Total & $\begin{array}{l}<1 \\
\geqslant 1\end{array}$ & $\begin{array}{r}3 \\
37\end{array}$ & $\begin{array}{l}0 \\
2\end{array}$ & $\begin{array}{l}19 \\
72\end{array}$ & $\begin{array}{r}0 \\
22\end{array}$ & $\begin{array}{l}30 \\
23\end{array}$ & $\begin{array}{l}1 \\
1\end{array}$ & $\begin{array}{l}29 \\
15\end{array}$ & $\begin{array}{l}5 \\
7\end{array}$ & $\begin{array}{r}81 \\
147\end{array}$ & $\begin{array}{r}6 \\
32\end{array}$ \\
\hline
\end{tabular}

those for the other hospitals in three of the four main groups into which the data are subdivided-that is, bilateral cases, whether young or old, and the older patients with unilateral tumours; in the younger patients with unilateral tumours no deaths were observed at any hospital. If due allowance is made for the differing ages and stages at which the cases were diagnosed, the results for the patients with unilateral tumours treated at group 1 hospitals were significantly better than for those treated at other hospitals $\left(\chi^{2}=6.65 ; 1\right.$ D.F.; $\mathbf{P}<0.01)$. For the bilateral cases the group 1 survival rate also seemed to be substantially better than that for cases at other hospitals, though the difference was not formally significant $\left(\chi^{2}=3.60,1\right.$ D.F.).

The apparently paradoxical finding that the overall survival rate for the bilateral cases was better than that for the unilateral cases is accounted for partly by the fact that there was a high proportion of early stage cases among the former and also that a much greater proportion of patients with bilateral tumours were treated at group 1 hospitals.

Group 1 cases included only those who received all their treatment at these two hospitals. There were in addition 20 patients (2 unilateral and 18 bilateral cases) who were initially treated at other hospitals and were subsequently referred to a group 1 hospital. One of the patients with a unilateral tumour and five of those with a bilateral one died. One possible explanation of these lower survival rates was that these children were selected for referral because of their bad prognosis.

It seems likely that all retinoblastoma patients would benefit from early referral to special units. Bedford et al. ${ }^{6}$ have suggested that such units should be fully equipped for all forms of treatment including radiotherapy, light coagulation, and cryotherapy.

\section{Other Neoplasms after Retinoblastoma}

Only one patient with retinoblastoma treated from 1962 to 1968 had developed a tumour of a different histological type when last followed up. This child had an osteosarcoma after bilateral retinoblastoma. The left eye was enucleated after diagnosis and the right eye had three separate courses of radiotherapy over the next three years and was then enucleated. Seven years after the first treatment the child died of osteosarcoma of the right orbit.

Scrutiny of the records of children under the age of 16 dying of cancer in Britain from 1961 to 1973 revealed eight other neoplasms after retinoblastomas. Seven children had received radiotherapy to the eye or socket; the eighth child, who developed an osteosarcoma of the femur, had received no radiotherapy. Six of these second neoplasms were osteosarcomas: three sited in the femur, one in the tibia, one in the orbit, and one in the maxilla; one child developed an angiosarcoma of the leg and one a fibrosarcoma of the antrum. The intervals between radiotherapy for the retinoblastoma and onset of the second neoplasm ranged from seven to 13 years.

Cases of retinoblastoma followed much later by osteosarcoma of the leg have been mentioned by other workers. ${ }^{4-9}$ Our findings lend support to the view that there may be an innate tendency towards osteosarcoma among survivors from retinoblastoma. An estimate of the actual magnitude of the risk will be presented in a later paper.

We thank Dr. Alice Stewart, formerly director of the Oxford Survey of Childhood Cancers, for her valuable help and advice. The survey is being continued by the Marie Curie Memorial Foundation under Dr. L. M. Kinnier Wilson. We thank all family doctors, medical officers of health, and hospital staff who helped in the collection of the data. We are grateful to Professor Sir Richard Doll, Mr. M. A. Bedford, and Mr. A. Bron for helpful comments, Dr. J. F. Bithell for statistical help, and Mrs. Betty Roberts for secretarial help.

The Childhood Cancer Research Group is supported by grants from the Department of Health and Social Security and the Scottish Home and Health Department. The survey of childhood cancers is supported by the Marie Curie Memorial Foundation and by grant number CA-12208 from the U.S. Public Health Service.

\section{References}

1 Mork, T., Acta Ophthalmologica, 1961, 39, 824.

2 Jensen, O. A., Acta Ophthalmologica, 1965, 43, 821.

3 Leelawongs, N., and Regan, C. D. J., American fournal of Ophthalmology, 1968, 66, 1050.

4 Jensen, R. D., and Miller, R. W., New England fournal of Medicine, 1971, 285, 307.

${ }^{5}$ Reese, A. B., and Ellsworth, R. M., Transactions of the American Academy of Ophthalmology and Otolaryngology, 1963, 67, 164.

6 Bedford, M. A., Bedotto, C., and MacFaul, P. A., British fournal of Ophthalmology, 1971, 55, 19.

7 Sagerman, R. H., et al., American fournal of Roentgenology, 1969, 105, 529. Glass, A. G., and Fraumeni, J. F., Fournal of the National Cancer Institute, $1970,44,187$.

${ }^{2}$ Kitchin, F. D., and Ellsworth, R. M., Fournal of Medical Genetics, 1974 11, 244. 